\title{
TOOTH BRUSH-TOOTH PASTE OCULAR INJURY: A SEQUELAE TO FAST LIFE
}

\author{
Anil Kumar Verma', Anil Chauhan², Rajeev Tuli³, Subhash Jaryal ${ }^{4}$
}

\section{HOW TO CITE THIS ARTICLE:}

Anil Kumar Verma, Anil Chauhan, Rajeev Tuli, Subhash Jaryal. "Tooth Brush-Tooth Paste Ocular Injury: A sequelae to Fast Life". Journal of Evolution of Medical and Dental Sciences 2015; Vol. 4, Issue 03 January 08; Page: 481-484, DOI: $10.14260 /$ jemds/2015/70

ABSTRACT: Toothbrush-tooth paste, widely used in every house hold, may cause irreversible injury to the eye especially cornea that comes into contact with this substance. We present two cases of toothbrush- toothpaste injury who accidentally injured their own eye. These were combination of chemical (Toothpaste) and trivial mechanical (Toothbrush) trauma. Ocular contact with toothpaste causes severe unbearable burning sensation. One of the cases developed suppurative corneal ulcer with hypopyon and lost vision in the affected eye. Toothpastes with more ph can cause blindness when it comes into contact with the eye if not treated urgently. The other patient (One of the consultants in our institute) reported immediately in the morning in emergency with complaints of severe burning sensation in the involved eye after accidental injury with toothbrush-toothpaste. His eyes were washed with normal saline for 30 to 40 minutes. Because he was treated immediately, he recovered within one week. Clinicians should take adequate precautions to prevent serious complication. In case of an accidental contact of eye with toothpaste, it is important to wash the eye efficiently. We decided to estimate the ph of commonly used various brands of toothpaste in over biochemistry lab and it was found that ph of various toothpaste varies from 7 to 10 . The $\mathrm{pH}$ of the brand of the toothpaste which was used by one of the case was ( $\mathrm{pH} 9.6)$, which shows that it is a combination of mechanical and alkali injury. pH near to neutral (7.1 and 7.4) was detected in one of the herbal toothpaste and one the oldest brand of toothpaste (Which was not herbal). These cases are being reported to make aware the ophthalmologists and public that although rare but these cases should not be taken lightly and should be treated urgently to prevent the loss of vision in the involved eye. One of the risk factors, may be the hurried activities in the morning in this era of fast life as one of the patients was working in a metropolitan city and the other a pathologist in our institution.

KEYWORDS: toothbrush, tooth paste, hypopyon, ph, cornel ulcer.

CASE 1: A 43 year old male (motor mechanic working in a service centre in Delhi) presented with history of injury with tooth brush-toothpaste in right eye five days back. Immediately he had severe burning sensation in the involved eye. He washed it with the tap water but did not get any relief. He gave history of OPD treatment in Delhi. But his symptoms did not improve. He came back to his native village in Himachal Pradesh and reported in our institution about a week after the onset injury. On day of presentation his BCVA in the right was HMCF and in the left eye was 20/20. There was no past history of diminution of vision in either eye. There was suppurative corneal ulcer in his right eye of size $9 \times 10 \mathrm{~mm}$ with hypopyon of height $2 \mathrm{~mm}$ which was thin and mobile (Figure-1). Other sections of the eye could not be examined clinically because of the lack of corneal translucency. Direct microscopy and culture examination of the corneal scrape was done. Pseudomonas aeruginosa was detected in BA, CA and BHI media on direct inoculation (Figure-2). Patient was treated with fortified cefazoline $5 \%$, fortified tobramycin $1.3 \%$, atropine eye drops $1 \%$, oral vitamin c $(500 \mathrm{mg}$ bid), oral antibiotic (ofloxacin 200mg bid) and tablet diamox 250mg tid. The ulcer healed within period of 4-6 
weeks but had developed a dense leucomatous corneal opacity with neovascularisation of cornea. (Figure -3)

CASE 2: A 45 year old male (a pathologist in our institute) presented in the morning in the emergency with history of injury in his right eye with toothbrush-toothpaste. He presented with the symptoms of severe burning sensation in his right. Immediately his right eye was irrigated with normal saline for continuous period of 30-40 minutes. A thorough eye washing by skill of turning the eyelid inside-out with normal saline was done. Punctate corneal fluorescein staining was positive, indicating damage to the cornea in his right eye. He was prescribed antibiotic eye drops moxifloxacin (0.5\%). His symptoms improved within 7-10 days. Visual acuity in both eyes was 6/6 after one week follow-up.

DISCUSSION: These both cases are a combination of chemical and trivial mechanical trauma to the eye. We decided to find out the nature of the chemical injury with toothpaste by collecting common brands of the toothpaste available in the market. The $\mathrm{pH}$ of various brands of toothpaste was estimated in dep't. Of biochemistry. It was found that the $\mathrm{pH}$ of the various toothpaste was in the range of $\mathrm{pH} 7.1$ to $\mathrm{pH} 10$.

\begin{tabular}{|c|c|l|c|}
\hline $\begin{array}{c}\text { SL. } \\
\text { No. }\end{array}$ & $\begin{array}{c}\text { BRAND OF } \\
\text { TOOTHPASTE }\end{array}$ & \multicolumn{1}{|c|}{ INGRADIENTS } & pH \\
\hline 1. & A & $\begin{array}{l}\text { Sodium monofluorophosphate, Calcium Carbonate, Water, Sorbital, } \\
\text { Hydrated Silica, Sodium Lauryl Sulphate, Flavor, Cellulose Gum, } \\
\text { Magnesium Aluminum Silicate, Sodium Carbonate, Sodium Saccharin, } \\
\text { Sodium Bicarbonate, Methylparaben, Propylparaben }\end{array}$ & 7.4 \\
\hline 2. & B & $\begin{array}{l}\text { Sorbitol, water, hydrated silica, sodium lauryl sulphate, Polyethylene } \\
\text { glycol-32, Zinc citrate, Flavor, cellulose gum, triclosan, sodium } \\
\text { saccharin, sodium fluoride, Cl74160 }\end{array}$ & 9.6 \\
\hline 3. & C & $\begin{array}{l}\text { Sorbitol, water, hydrated silica, Polyethylene glycol-32, sodium lauryl } \\
\text { sulfate, SD alcohol 38 b (grain alcohol), flavor, cellulose gum, sodium } \\
\text { saccharin, red 33, red 40, mica. }\end{array}$ & 8.1 \\
\hline 4 & D & Clove oil, Pudina Satwa, Tomar Beej, Sunthi (Ginger): & 9.2 \\
\hline 5 & E & $\begin{array}{l}\text { Pomegranate, Neem, Indian Gum Arabic Tree's fresh twigs Triphala, } \\
\text { Bishop's Weed, False Black Pepper, Five-Leaved Chaste Tree }\end{array}$ & 7.1 \\
\hline
\end{tabular}

TABLE 1: Estimated pH of commonly available brands of toothpaste in the market

With reference to table no.1 brand B and D had pH9.6 and 9.2. (Alkaline). Accidental contact of more alkaline toothpastes can cause damage to the eye if it is not thoroughly washed with water or normal saline especially by an ophthalmologist by thorough cleaning of fornices and inner aspect of eye lids.

Alkali injury are typically more serious because the alkali can rapidly penetrate the cornea into the anterior chamber of the eye within few minutes and damage the iris, cilliary body, lens and trabecular network. Alkali damage includes saponification of cell membranes, cell death and disruption of the extracellular matrix. Alkalis can continue destroying tissues within the eye for several days. Penetration rates differ with different types of alkalis. Training health care personnel in 


\section{CASE REPORT}

the skills of turning the eyelid inside-out and thorough eye washing on site within the first few minutes of an accident is of prime importance. According to the latest guidelines, the eye should be washed for several minutes (30-40 minutes) with saline or tap water and specialist help and treatment should be sought immediately after washing is completed.[1]

Both patients may be in hurry in the morning as fast life of metropolitan cities (Case-1, a motor mechanic in Delhi) and fast life of a medical professional (Case-2 a pathologist in our institution) may be one of the risk factors of accidental toothbrush- toothpaste ocular injury.

CONCLUSION: This case report emphasizes the importance of taking special care while using tooth brush and toothpaste, a commonly used in every house hold, to avoid eye contamination because it can cause blindness. If eye is accidently injured with tooth paste and tooth brush, the eyelid flip should be done immediately with copious washing, followed by prompt ophthalmologic consultation.

\section{REFERENCES:}

1. Lipski M, Buczkowska-Radlińska J \& Góra M. Loss of Sight Caused by Calcium Hydroxide Paste Accidentally Splashed into the Eye during Endodontic Treatment: Case Report. J Can Dent Assoc. 2012; 78: c57.

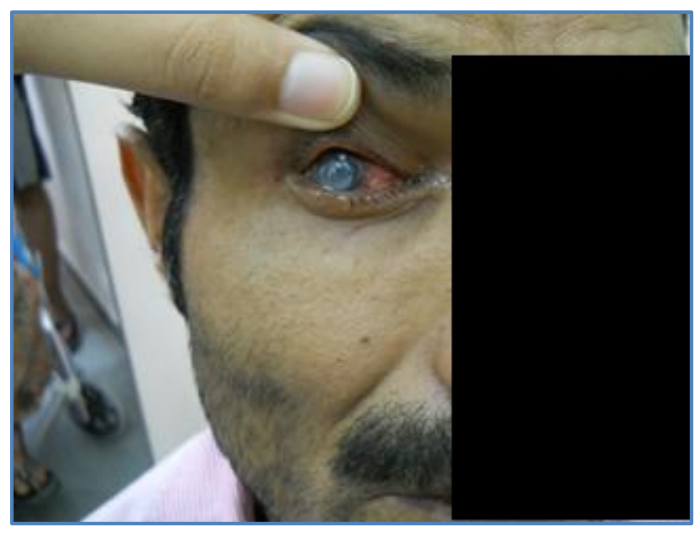

Fig. 1: Suppurative corneal ulcer in right eye
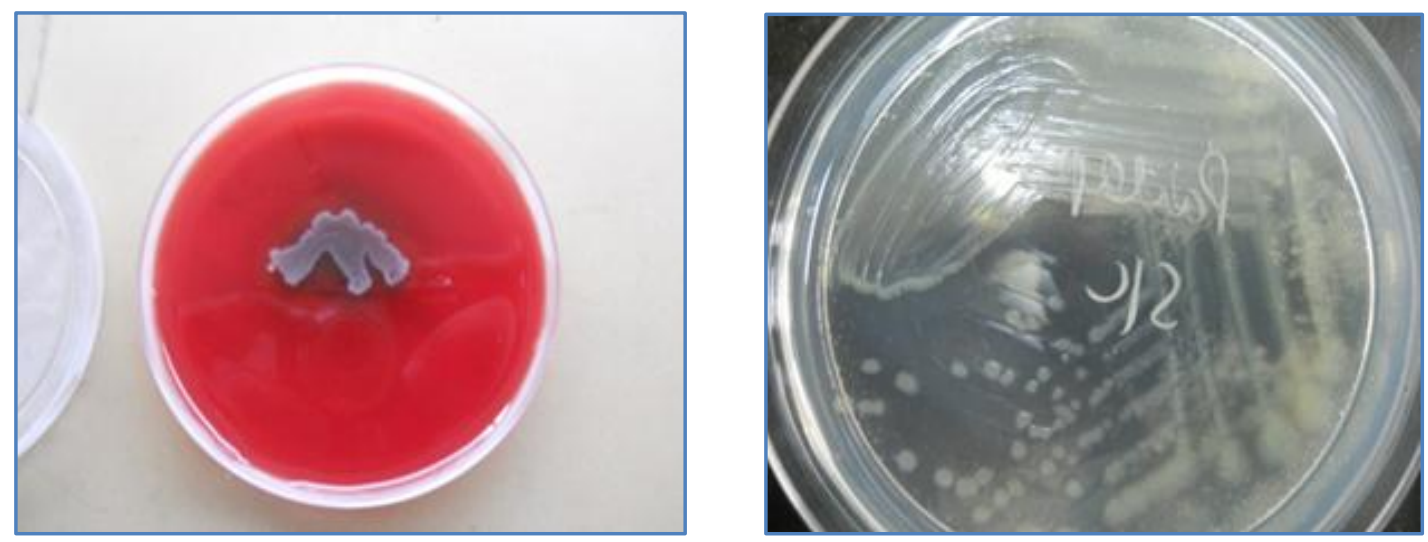

Fig. 2: Pseudomonas aeruginosa was detected in culture 


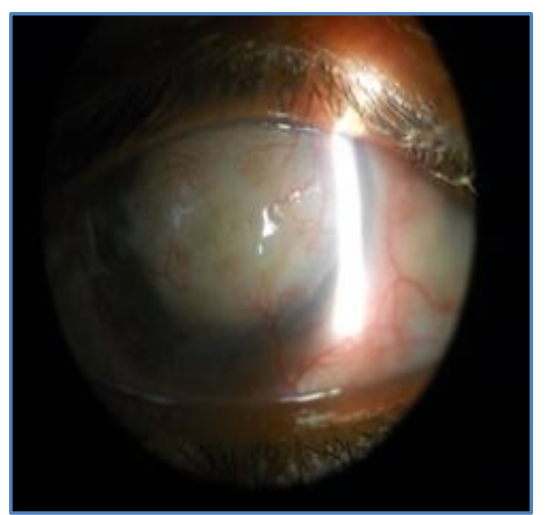

Fig. 3: Leucomatous corneal opacity with vascularization

\section{AUTHORS:}

1. Anil Kumar Verma

2. Anil Chauhan

3. Rajeev Tuli

4. Subhash Jaryal

\section{PARTICULARS OF CONTRIBUTORS:}

1. Senior Resident, Department of Ophthalmology, Dr. R. P. G. M. C. Kangra at Tanda, Himachal Pradesh.

2. Professor, Department of Ophthalmology, Dr. R. P. G. M. C. Kangra at Tanda, Himachal Pradesh.

3. Professor, Department of Ophthalmology, Dr. R. P. G. M. C. Kangra at Tanda, Himachal Pradesh.
4. Associate Professor, Department of Microbiology, Dr. R. P. G. M. C. Kangra at Tanda, Himachal Pradesh.

\section{NAME ADDRESS EMAIL ID OF THE CORRESPONDING AUTHOR:}

Dr. Anil Kumar Verma, Senior Resident, Department of Ophthalmology, Dr. R. P. G. M. C. Kangra at Tanda, Himachal Pradesh.

E-mail: anilkumarverma2971@gmail.com

Date of Submission: 17/12/2014. Date of Peer Review: 18/12/2014. Date of Acceptance: 31/12/2014. Date of Publishing: 07/01/2015. 